\title{
Endonasal management of pediatric congenital transsphenoidal encephaloceles: nuances of a modified reconstruction technique. Technical note and report of 3 cases
}

\author{
Mehdi Zeinalizadeh, MD, ${ }^{1,2}$ Seyed Mousa Sadrehosseini, MD, ${ }^{3}$ Zohreh Habibi, MD, ${ }^{4}$ \\ Farideh Nejat, MD, ${ }^{4}$ Harley Brito da Silva, MD, ${ }^{5}$ and Harminder Singh, MD ${ }^{6}$

\begin{abstract}
'Brain and Spinal Cord Injuries Repair and Research Center, ${ }^{2}$ Department of Neurological Surgery, and ${ }^{3}$ Department of Otolaryngology-Head \& Neck Surgery, Imam Khomeini Hospital Complex, Tehran University of Medical Sciences; and ${ }^{4}$ Department of Neurological Surgery, Children's Medical Center, Tehran University of Medical Sciences, Tehran, Iran; ${ }^{5}$ Department of Neurological Surgery, Harborview Medical Center, University of Washington, Seattle, Washington; and
\end{abstract} \\ ${ }^{6}$ Department of Neurological Surgery, Stanford University School of Medicine, Stanford, California
}

OBJECTIVE Congenital transsphenoidal encephaloceles are rare malformations, and their surgical treatment remains challenging. This paper reports 3 cases of transsphenoidal encephalocele in 8- to 24-month-old infants, who presented mainly with airway obstruction, respiratory distress, and failure to thrive.

METHODS The authors discuss the surgical management of these lesions via a minimally invasive endoscopic endonasal approach, as compared with the traditional transcranial and transpalatal approaches. A unique endonasal management algorithm for these lesions is outlined. The lesions were repaired with no resection of the encephalocele sac, and the cranial base defects were reconstructed with titanium mesh plates and vascular nasoseptal flaps.

RESULTS Reduction of the encephalocele and reconstruction of the skull base was successfully accomplished in all 3 cases, with favorable results.

CONCLUSIONS The described endonasal management algorithm for congenital transsphenoidal encephaloceles is a safe, viable alternative to traditional transcranial and transpalatal approaches, and avoids much of the morbidity associated with these open techniques.

https://thejns.org/doi/abs/10.3171/2016.10.PEDS16270

KEY WORDS congenital; transsphenoidal encephalocele; endonasal; endoscopy; reconstruction

$\Delta$ CONGENITAL encephalocele is defined as a herniation of cranial contents through a cranial defect in a patient with a medical history negative for secondary causes..$^{17}$ Basal encephaloceles are rare, with an estimated incidence of 1 in every 35,000 live births. They are classified into transethmoidal, sphenoorbital, sphenomaxillary, and transsphenoidal. ${ }^{19}$ Transsphenoidal encephaloceles are the rarest of the rare, accounting for 5\% of basal herniations, and having an estimated incidence of 1 in 700,000 live births. ${ }^{7}$ Transsphenoidal encephaloceles have a higher incidence in Southeast Asia than in Western countries. ${ }^{17}$
Numerous theories have been proposed to explain the cause of the disease. It has been defined as a multifactorial condition, with a combination of genetic and environmental factors leading to the failure of the neural tube to fuse at the level of the anterior neuropore. ${ }^{11,19}$ Neural tissue overgrowth, viral infection, radiation, hyperthermia, hypervitaminosis, salicylates, trypan blue, hypoxia, and numerous other agents have been suggested as causes of persistent openings in the neural tube. ${ }^{3}$

Transsphenoidal encephaloceles are usually diagnosed in very young pediatric patients and are commonly as-

ABBREVIATIONS NSF $=$ nasoseptal flap; TMP = titanium mesh plate. 
sociated with pituitary dysfunction and visual problems attributable to the distension of the pituitary gland, hypothalamus, and optic pathway within the sac..$^{17}$ The lesions are not externally visible; thus the age at clinical diagnosis is largely determined by the size of the encephalocele, related anomalies, and presence or absence of respiratory difficulties. ${ }^{15,18}$ Signs and symptoms include upper airway obstruction, snoring, pulsatile mass, endocrine abnormalities, recurrent meningitis, CSF rhinorrhea, or purulent discharge in the nasopharynx. ${ }^{1,20,21}$

The surgical treatment of transsphenoidal encephaloceles remains a challenge because of the involvement of opticochiasmatic structures, the hypothalamopituitary axis, and the proximity to the anterior and middle fossa vessels. ${ }^{9}$ The common approaches to repair these malformations are transcranial, endoscopic endonasal, and transpalatal. ${ }^{21}$ The method of treatment varies according to the experience of the surgical team involved, and an ideal approach has yet to be validated. ${ }^{2}$

We report our experience with a series of 3 cases of congenital transsphenoidal encephaloceles that were successfully managed using an endonasal endoscopic approach. We describe the technical nuances involved in managing the encephaloceles and reconstructing the cranial base defect.

\section{Case Reports}

\section{Case 1}

An 18-month-old girl presenting with nasal airway obstruction was initially referred to the hospital for a cleft lip repair. Preoperative clinical examination revealed a cleft lip as well as hypertelorism. Preoperative MRI studies showed a midline nasopharyngeal encephalocele of the structures around the third ventricle and hypothalamic area. The encephalocele extended from the suprasellar space through the defect in the sphenoid bone into nasopharyngeal, nasal, and oropharyngeal cavities (Fig. 1A-C). The other MRI finding was of corpus callosum agenesis. The CT scans showed the large skull base defect (Fig. 1D). Preoperative endocrinological and ophthalmological findings were considered to be normal.

The patient underwent an endoscopic endonasal approach for repair of the encephalocele sac and bony defect as described below. She recovered extremely well after the surgery; she was on an oral diet on the 2nd postoperative day, and was discharged on Day 7 after the removal of nasal compressive packing and the postoperative CT scan (Fig. 1E). The patient had an uneventful recovery after her hospital discharge, and had no further respiratory distress, CSF leak, or endocrinological changes. The outpatient endoscopic follow-up at 1 month showed good healing of the mucosa and no CSF leak. Postoperative MRI studies at 3,12 , and 24 months demonstrated no evidence of recurrence of the encephalocele sac (Fig. 1F).

\section{Case 2}

A 24-month-old boy presenting with failure to thrive, cleft lip, nasal obstruction, polydipsia, and polyuria was referred to the hospital for the treatment of nasal airway obstruction and cleft lip. The preoperative MRI and CT scans revealed agenesis of the corpus callosum, and a
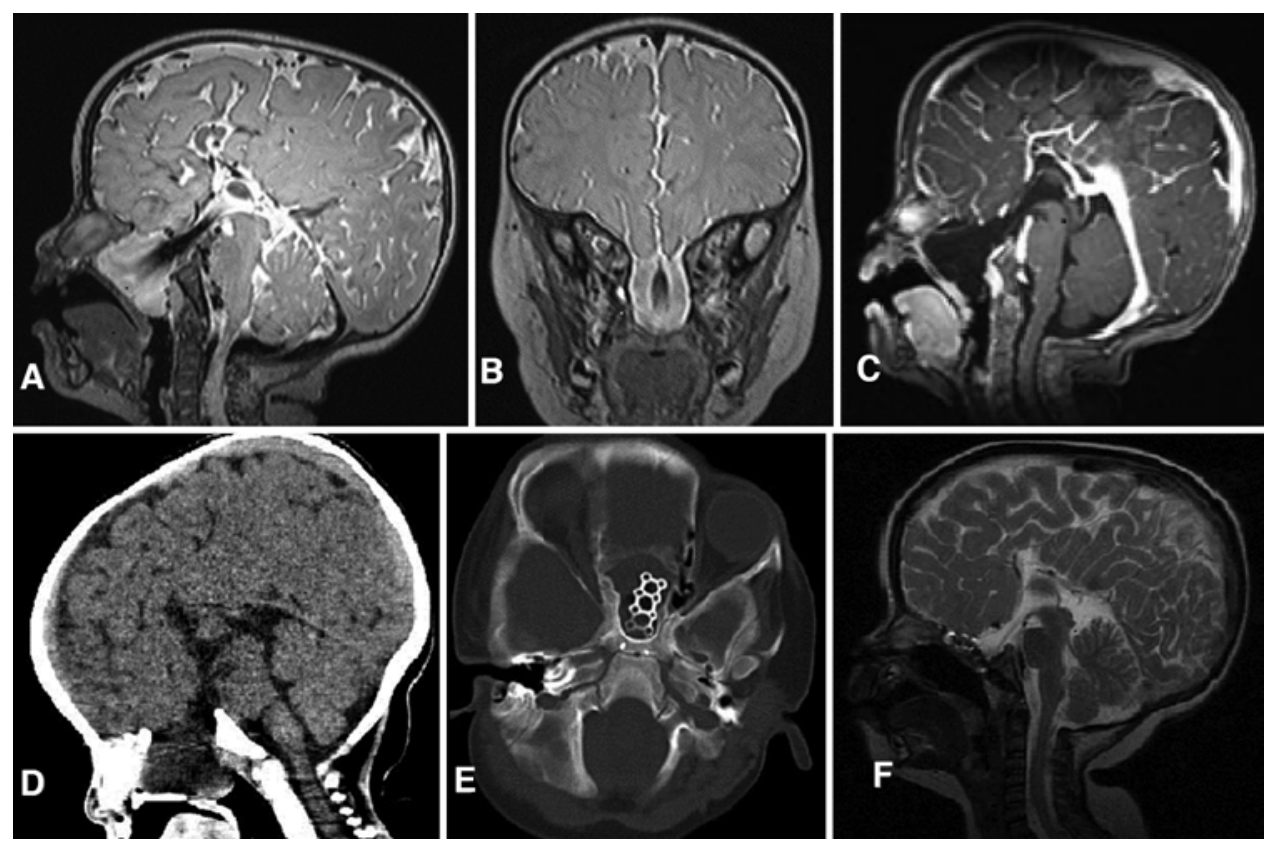

FIG. 1. Case 1. A-C: Preoperative sagittal and coronal T2- and sagittal T1-weighted MRIs obtained with gadolinium contrast revealing a midline soft-tissue mass without enhancement consisting of mainly dysplastic brain tissue, and CSF extending from the suprasellar space and third ventricle through the body of the sphenoid bone into the nasopharynx, nasal cavity, and oropharynx. D: Preoperative reconstructed sagittal CT scan showing a large defect in the sphenoid bone through which the encephalocele has herniated. E: Early postoperative CT scan with bone windows showing the placement of a TMP affixed to the clivus. F: Postoperative sagittal T2-weighted MRI study obtained at 1 year demonstrating no evidence of recurrence of the nasal encephalocele. The oronasopharyngeal airway is patent. 
transsellar, transsphenoidal meningoencephalocele that protruded through a large skull base defect in the middle of the sphenoid bone (Fig. 2A-C). The patient underwent surgical correction of the encephalocele via an endoscopic endonasal approach. The postoperative course was uneventful and the patient began an oral diet on postoperative Day 1. Postoperative CT scanning (Fig. 2D and E) was performed and the patient was discharged on postoperative Day 7. Six months later he underwent the repair of his cleft lip. An MRI study was obtained at his 6-month follow-up (Fig. 2F). At his 1-year follow-up the patient had regained the normal weight for his age, and had no CSF leak or any other complications.

\section{Case 3}

An 8-month-old girl on mechanical ventilation was transferred to the hospital after an acute episode of pneumonia and upper airway obstruction. The MRI studies and bone window CT scan revealed a transsphenoidal meningoencephalocele herniating through the floor of the sella turcica and sphenoid sinus (Fig. 3A-C), as well as agenesis of the corpus callosum. Pituitary hormonal secretion test results were within normal range. Surgical repair and reconstruction was performed via an endoscopic endonasal approach as described below. Postoperatively, the patient had a transient episode of diabetes insipidus that was clinically treated. She also developed pneumonia for which she had to remain on mechanical ventilation for 7 days. She was discharged from the hospital after undergoing her pneumonia treatment for 2 weeks. A CT scan was performed prior to patient discharge (Fig. 3D and E), and an MRI study was performed at 6 months' (Fig. 3F) follow-up, showing complete resolution of the meningoencephalocele.

\section{Surgical Technique}

The endoscopic endonasal approach with neuronavigation was used for all 3 patients. After induction of general anesthesia, the patient was placed supine with the head positioned on a horseshoe headholder in slight extension. After preparing the surgical field with a nonalcoholic antiseptic solution and giving prophylactic intravenous antibiotics (cefazoline $12.5 \mathrm{mg} / \mathrm{kg}$ before starting surgery and repeated every 3 hours), the nasal passages were prepared with a solution of 1:100,000 epinephrine and 1\% lidocaine. Rigid-rod endoscopes, with lenses $4 \mathrm{~mm}$ in diameter, were mounted on a digital video camera system (Karl Storz, Inc.).

We first assessed the extent of the nasopharyngeal mass by advancing the $0^{\circ}$ endoscope into the nasal cavity. The mass was adherent anteriorly to the posterior septum and superoposteriorly to the roof of the nasopharynx. The bilateral middle and inferior turbinates and soft palate were preserved. We applied a surgical technique consisting of 6 steps in all 3 cases (Video 1), as follows.

VIDEO 1. Intraoperative video demonstrating the technique for the repair of a transsphenoidal encephalocele in an infant. All 6 steps of the surgical technique are illustrated. Copyright Seyed Mousa Sadrehosseini. Published with permission. Click here to view.

\section{Septal Flap Preparation}

A standard Hadad-Bassagasteguy nasoseptal flap (NSF) was harvested on the right side for reconstruc-
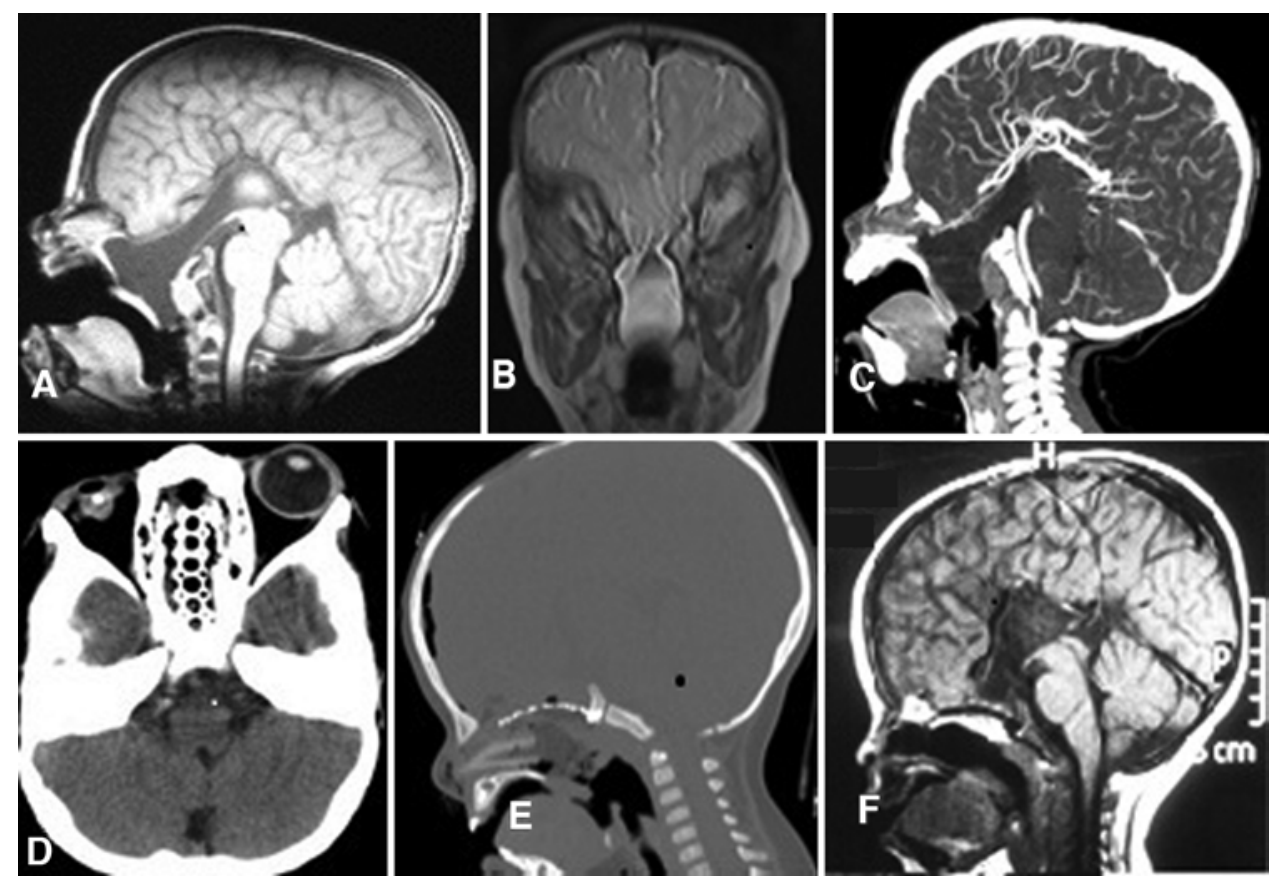

FIG. 2. Case 2. A and B: Preoperative sagittal T1- and coronal T2-weighted MR images demonstrating a transsphenoidal encephalocele. C: Preoperative reconstructed sagittal CT scan with contrast injection revealing a large defect in the body of the sphenoid bone, with a transsphenoidal encephalocele. D and E: Early postoperative axial and reconstructed sagittal CT scans showing the position of the TMP affixed to the clivus, as well as a small amount of pneumocephalus in the frontal area. F: Postoperative MRI study demonstrating reduction of encephalocele and a patent airway at 3 months. 

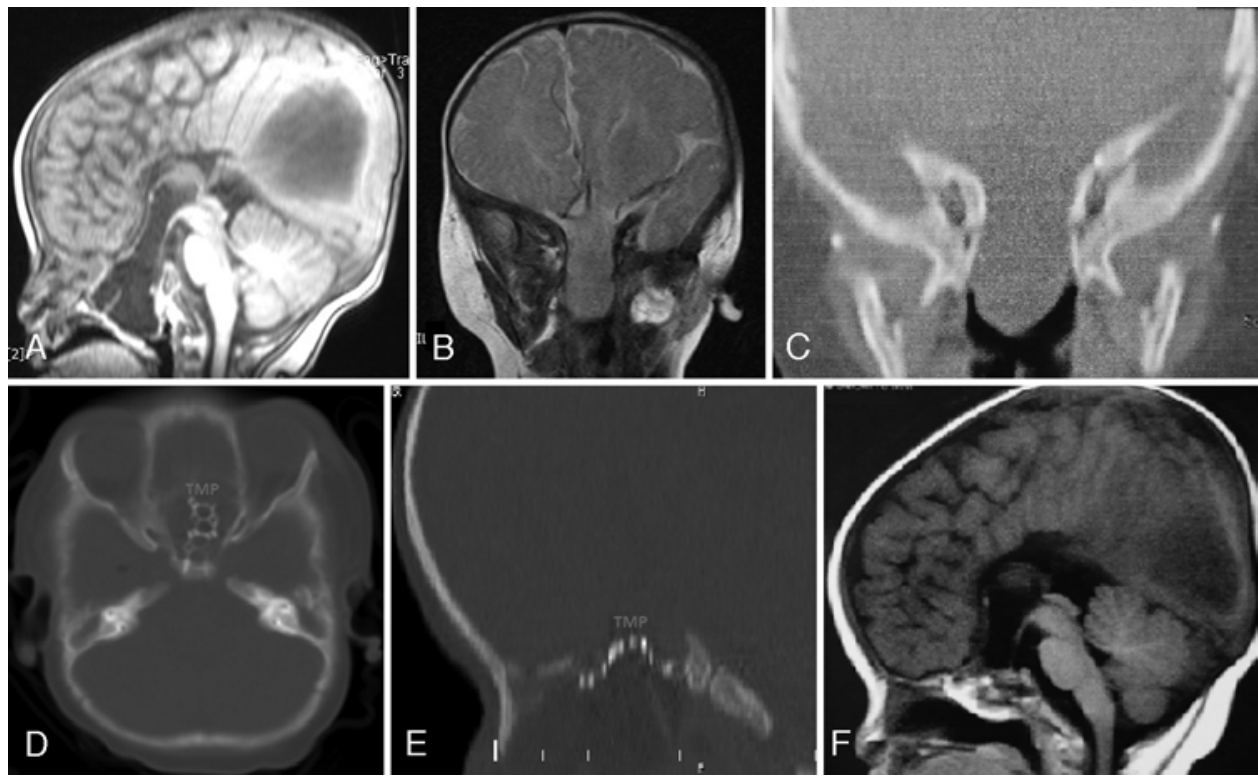

FIG. 3. Case 3. A and B: Sagittal T1- and coronal T2-weighted MR images showing a large transsphenoidal encephalocele communicating with the third ventricle. C: A large bone defect with herniation of encephalocele sac is seen in the reconstructed coronal view on a CT scan. D and E: Early postoperative axial and reconstructed sagittal CT scans with bone windows showing the position of the affixed TMP. F: A follow-up postoperative T1-weighted MRI study obtained at 6 months demonstrating excellent repair of the encephalocele and cranial base defect, thus improving airflow through the nasooropharynx.

tion of the preexisting skull base defect (Fig. 4A). With the help of monopolar cautery and blunt dissection, the anterior attachment of the encephalocele to the posterior septum was disconnected.

\section{Meningoencephalocele Sac Aspiration}

Under neuronavigation guidance, a 23-gauge spinal needle was introduced into the anterior inferior portion of the lesion, away from any critical neurovascular structures (Fig. 4B), and 30-40 $\mathrm{ml}$ of CSF was gradually drained to decompress the meningoencephalocele sac.

\section{Dissection of the Mucosal Layer From the Meningoencephalocele Sac}

The nasal mucosa was dissected off the encephalocele sac in an anterior to posterior, and superior to inferior, direction (Fig. 4C). Gradually, the sac was entirely separated from the surrounding mucosal layer with no overt rupture; pinhole tears in the sac were unavoidable, however. Resection of anomalous herniated brain elements was not performed, except for taking a small biopsy sample from the most posterior-inferior portion of the encephalocele.

\section{Reduction of Herniated Encephalocele Sac}

The herniated encephalocele sac was gradually pushed back into normal anatomical alignment to the floor of the cranial base dura mater (Fig. 4D).

\section{Reconstruction of the Bony Cranial Base Defect}

The defect was overlaid by a free fascia lata graft. A small titanium mesh plate (TMP) was affixed to the clivus inferiorly with screws, and was wedged underneath the bony edge anterosuperiorly, reconstructing the skull base (Figs. 4E, 5, and 6). Last, the area was covered with a standard posterior pedicle NSF.

\section{Reconstruction of Donor NSF Cartilage}

The NSF donor site was reconstructed using a free fascia lata graft (Fig. 4F).

All patients received postoperative parenteral antibiotics for a period of 24 hours, except in the third one, in whom antibiotics were continued for 14 days because of development of pneumonia. Immediate postoperative CT scans were obtained routinely in all patients to evaluate the skull base reconstruction and the positioning of the TMP.

\section{Discussion}

Midline craniofacial defects such as cleft palate and cleft lip, hypertelorism, hydrocephalus, and corpus callosum agenesis are often associated with basal encephaloceles (Fig. 5). Also, the association of morning glory syndrome, characterized by a congenital dysplasia of the optic disc, is common..$^{20,21}$ All 3 cases reported here had corpus callosum agenesis-optic disc anomalies, however, were not detected.

The majority of transsphenoidal meningoencephaloceles are diagnosed during the 1st year of life due to manifestations such as respiratory distress and feeding difficulties caused by airway obstruction, recurrent meningitis, endocrine abnormalities, or associated congenital cranial midline anomalies. ${ }^{8}$ In the absence of these, the diagnosis may be delayed into adolescence or adulthood. ${ }^{9}$ In our patients, airway obstruction and respiratory distress, cleft lip, failure to thrive, and diabetes insipidus were the main signs and symptom of presentation. 

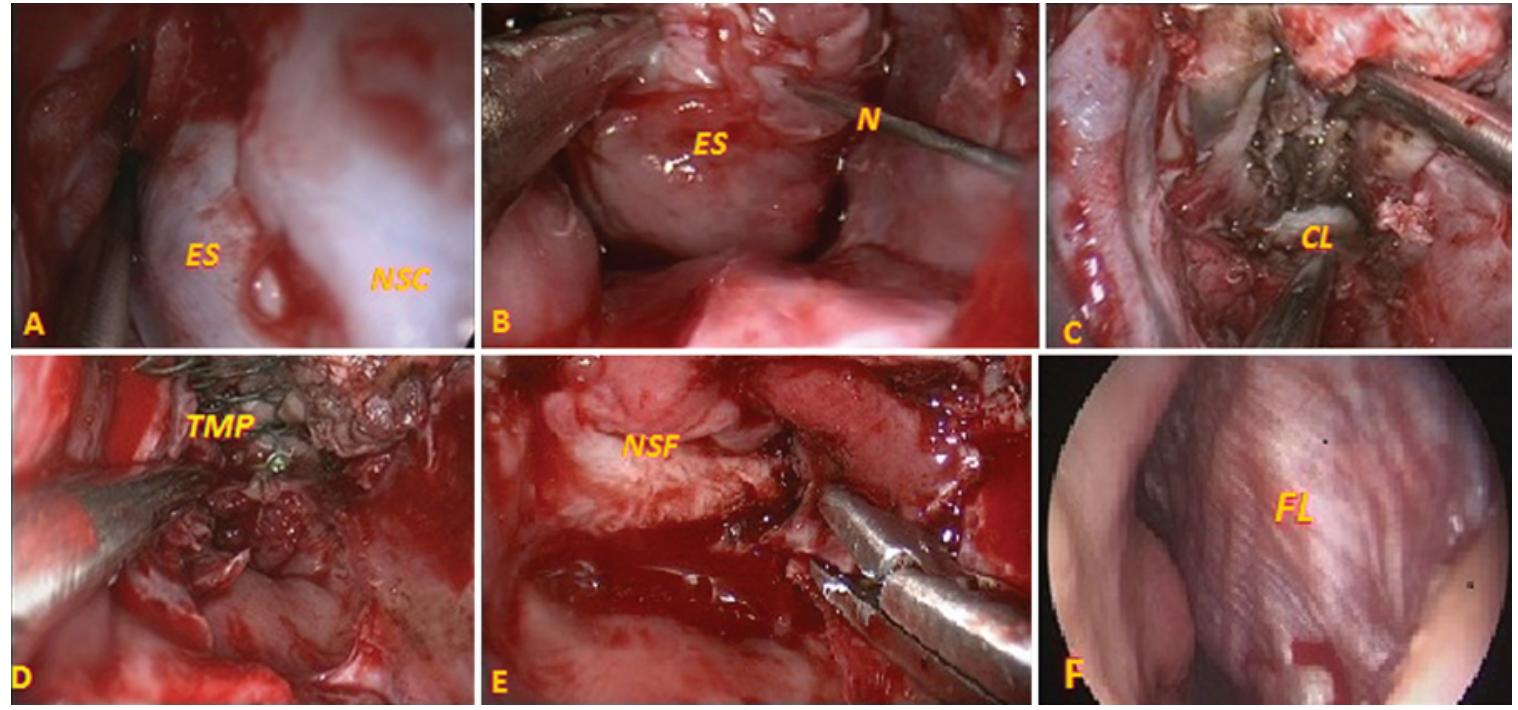

FIG. 4. Endoscopic views via the right nasal cavity demonstrating the technique for the repair of a transsphenoidal encephalocele. A: Intraoperative view of denuded nasal septal cartilage (NSC) after harvesting a Hadad-Bassagasteguy flap and exposing the anterior surface of the encephalocele sac (ES). B: Aspiration of the sac by means of a 23-gauge spinal needle (N) from the anterior inferior portion of the lesion. C: Reducing the sac to a normal anatomical position of the cranial base dura mater near the floor of the sellar area and exposing the clivus (CL). D: Reconstruction of the bony cranial base defect with a TMP affixed to the clivus. E: The final position of the standard posterior pedicle NSF. F: Intraoperative view of the donor septal site reconstructed with a fascia lata graft (FL). Figure is available in color online only.

Preoperative MRI and CT scans are crucial to assess associated brain abnormalities, and to identify vital structures in the herniated sac such as the pituitary gland, hypothalamus, optic pathways, and vascular anatomy. They are also invaluable for surgical planning and follow-up.18 Therefore, after a careful analysis of our patients' preoperative imaging, we designed the safest approach to avoid any damage to critical neurovascular structures during surgical management of the encephalocele.

Consensus management of transbasal transsphenoidal encephaloceles, including the indication, timing, and the optimal mode of treatment has yet to be established. Strong indications for surgery include the following: persistent CSF leak, recurrent meningitis, progression of neurological deficits, and respiratory distress. The close relationship of transsphenoidal encephaloceles with the hypothalamus, pituitary gland, and optic pathway poses a surgical challenge, particularly in the pediatric population. Reported surgical approaches for transsphenoidal encephaloceles include transpalatal, transcranial, and endoscopic endonasal or combined approaches. ${ }^{2,18}$

In cases of transsphenoidal encephaloceles in patients with large cleft palate defects, transpalatal approaches are preferred by most authors. However, performing palatal osteotomies and removing the hard palate may be technically challenging and create additional difficulties for the reconstruction of the skull base and closure of the mucosal layer ${ }^{8,10}$ Furthermore, splitting of the palate can result in delayed palatal wound healing, palatal dehiscence, and prolonged enteral tube feeding due to velopharyngeal insufficiency. ${ }^{6,17}$ The transpalatal route was not our choice because our patients did not have a cleft palate and we intended to minimize the invasiveness of the procedure.

The transcranial subfrontal or pterional approach adds additional technical difficulties to a case of transsphenoidal encephalocele because of the retrochiasmatic location of the encephalocele, as well as the proximity of the pituitary stalk and hypothalamus. Therefore, these approaches

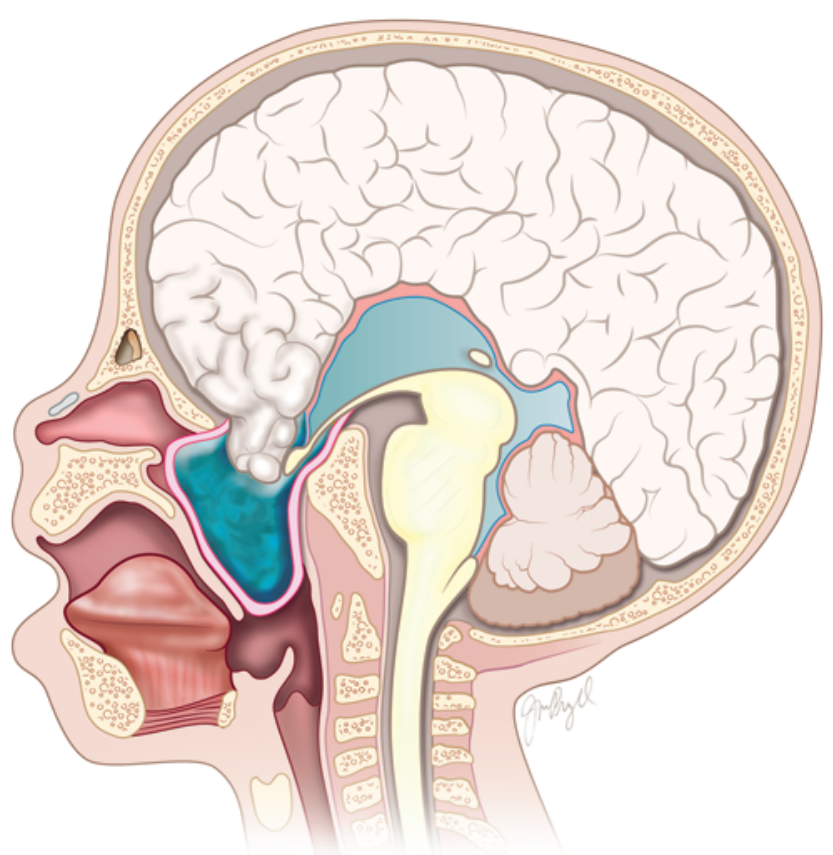

FIG. 5. Artist's rendition of a basal encephalocele in a pediatric patient, shown in sagittal projection. Note the herniated encephalocele sac crowding the nasooropharynx, which leads to respiratory distress. Copyright Harminder Singh. Published with permission. Figure is available in color online only. 


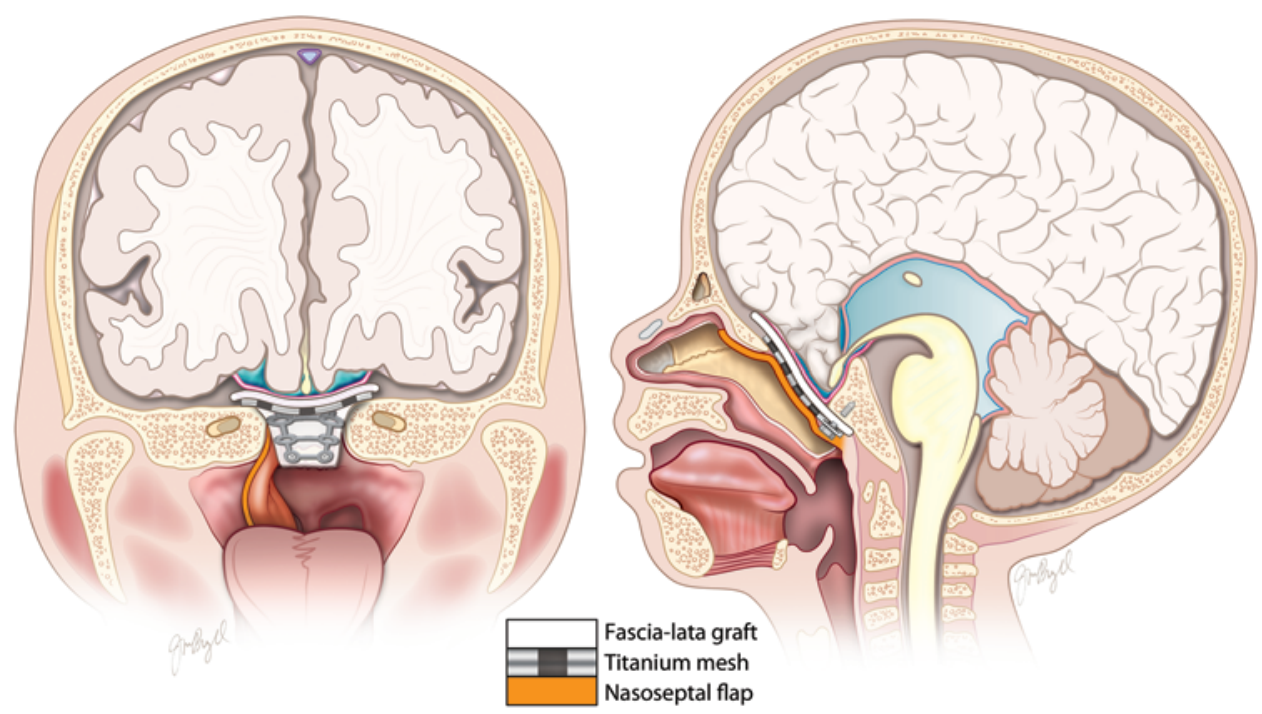

FIG. 6. Artist's rendition of multilayered skull base closure after reduction of an encephalocele. Left: Coronal view. Right: Sagittal view. Copyright Harminder Singh. Published with permission. Figure is available in color online only.

are associated with high postoperative rates of morbidity, mortality, and hypothalamic dysfunction. Furthermore, infants are more susceptible to retraction injuries with subfrontal or frontotemporal approaches. ${ }^{16,18}$

The most common surgical strategy for these cases is partial or total excision of the sac. ${ }^{8,10,17,18}$ Our technique described above has an important advantage in that there is no need to resect the herniated sac. After CSF drainage through a small-bore needle, we were able to dissect the mucosal layer off of the encephalocele sac and reduce the sac into the intracranial cavity at the skull base. This was achieved in all 3 cases, even when there was severe adherence of the sac to the mucosal layer.

In our series, we did not attempt to reduce the encephalocele sac via use of a lumbar drain. Lumbar drainage has been successfully used by surgeons during pituitary surgery to reduce intracranial pressure and prevent ballooning of the diaphragma into the surgical field. Meningoencephalocele sacs, however, can sometimes develop pseudomembranes, which act as 1-way valves and prevent ingress of CSF back into the intracranial subarachnoid space. In such cases, lumbar drainage may or may not be effective in reducing the encephalocele.

Recently, a combined transnasal/transoral endoscopic approach in a 17-day-old boy ${ }^{18}$ has been reported, but generally in children younger than 1 year, only the transpalatal approach has been used. In our series, we demonstrate that a purely endonasal endoscopic approach can be used safely in this age group. The endoscope allowed wide-angled, close-up views with optimal visualization through a narrow surgical corridor. In contrast to some authors who believe that, for complex cases, complete repair is impossible and thus suggest nonradical surgery, ${ }^{9}$ we achieved a thorough repair and good cranial base reconstruction via the endonasal route, even without removing the turbinates.

The other unique aspects of our modified technique were the reconstruction of the bony defect with a TMP, the use of a pedicled NSF even in an 8-month-old patient, and the reconstruction of the NSF donor site with a fascia lata graft $^{22}$ (Fig. 6). Also, intraoperative CSF aspiration, through a safe zone of encephalocele sac by means of a small-bore spinal needle, precludes the necessity of preor intraoperative external ventricular or lumbar drainage.

Treatment of transsphenoidal encephaloceles in the pediatric population has been previously associated with postoperative complications including palatal dehiscence, recurrence of encephalocele, CSF leak, and meningitis. ${ }^{18}$ Moreover, death has been described in many reports. ${ }^{4,13,14}$ Previous reports have shown that the rates of mortality and morbidity or long-term severe disability, mainly through transcranial surgery, approached $50 \%$ and $70 \%$, respectively. ${ }^{5,12}$ We encountered no major complications in our series of patients. Our follow-up ranged from 12 to 24 months, and none of the patients had recurrence of the encephaloceles.

\section{Conclusions}

The surgical management of transsphenoidal encephaloceles with a descended voluminous sac into the nasooropharynx has been challenging in the pediatric population. We describe a safe technique with favorable initial results. The endoscopic endosnasal approach with no excision of encephalocele sac is a minimally invasive, safe, and feasible alternative, even for children younger than 1 year of age. However, the importance of a dedicated surgical team, consisting of an experienced otolaryngologist and neurosurgeon, is critical for its success.

\section{Acknowledgments}

We thank Cindy H. Samos for manuscript editing.

\section{References}

1. Abdel-Aziz M, El-Bosraty H, Qotb M, El-Hamamsy M, ElSonbaty M, Abdel-Badie H, et al: Nasal encephalocele: endoscopic excision with anesthetic consideration. Int J Pediatr Otorhinolaryngol 74:869-873, 2010 
2. Abe T, Lüdecke DK, Wada A, Matsumoto K: Transsphenoidal cephaloceles in adults. A report of two cases and review of the literature. Acta Neurochir (Wien) 142:397-400, 2000

3. Cinalli G, Maixner WJ, Sainte-Rose C: Pediatric Hydrocephalus. Milan: Springer, 2004

4. David DJ: Cephaloceles: classification, pathology, and management-a review. J Craniofac Surg 4:192-202, 1993

5. David DJ, Proudman TW: Cephaloceles: classification, pathology, and management. World J Surg 13:349-357, 1989

6. Formica F, Iannelli A, Paludetti G, Di Rocco C: Transsphenoidal meningoencephalocele. Childs Nerv Syst 18:295298, 2002

7. French BN: Midline fusion defects and defects of formation, in Youmans JR (ed): Neurological Surgery. Philadelphia: Saunders, 1982, pp 1236-1380

8. Goodrich JT: Pediatric Neurosurgery. New York: Thieme, 2008, pp 69-75

9. Herman P, Sauvaget E, Guichard JP, Tran Ba Huy P: Intrasphenoidal transsellar encephalocele repaired by endoscopic approach. Ann Otol Rhinol Laryngol 112:890-893, 2003

10. Kahyaoğlu O, Cavuşoğlu H, Müslüman AM, Kaya RA, Yilmaz A, Sahin Y, et al: Transsellar transsphenoidal rhinooral encephalocele. Turk Neurosurg 17:264-268, 2007

11. Kindler P: Morning glory syndrome: unusual congenital optic disk anomaly. Am J Ophthalmol 69:376-384, 1970

12. Mahapatra AK, Suri A: Anterior encephaloceles: a study of 92 cases. Pediatr Neurosurg 36:113-118, 2002

13. Raman Sharma R, Mahapatra AK, Pawar SJ, Thomas C, Al-Ismaily M: Trans-sellar trans-sphenoidal encephaloceles: report of two cases. J Clin Neurosci 9:89-92, 2002

14. Rathore YS, Sinha S, Mahapatra AK: Transsellar transsphenoidal encephalocele: a series of four cases. Neurol India 59:289-292, 2011

15. Sasani M, Ozer AF, Aydin AL: Endoscopic treatment of trans-sellar trans-sphenoidal encephalocele associated with morning glory syndrome presenting with non-traumatic cerebrospinal fluid rhinorrhea. J Neurosurg Sci 53:31-35, 2009

16. Sinha S, Mirza S, Bishop N, Zaki H, McMullan J: Endoscopic endonasal resection of the odontoid peg for paediatric basilar invagination. Br J Neurosurg 26:487-489, 2012

17. Spacca B, Amasio ME, Giordano F, Mussa F, Busca G, Donati $P$, et al: Surgical management of congenital median perisellar transsphenoidal encephaloceles with an extracranial approach: a series of 6 cases. Neurosurgery 65:1140-1146, 2009

18. Steven RA, Rothera MP, Tang V, Bruce IA: An unusual cause of nasal airway obstruction in a neonate: trans-sellar, transsphenoidal cephalocoele. J Laryngol Otol 125:1075-1078, 2011
19. Suwanwela C, Suwanwela N: A morphological classification of sincipital encephalomeningoceles. J Neurosurg 36:201211,1972

20. Tan SH, Mun KS, Chandran PA, Manuel AM, Prepageran N, Waran V, et al: Combined transnasal and transoral endoscopic approach to a transsphenoidal encephalocele in an infant. Childs Nerv Syst 31:1165-1169, 2015

21. Tirumandas M, Sharma A, Gbenimacho I, Shoja MM, Tubbs RS, Oakes WJ, et al: Nasal encephaloceles: a review of etiology, pathophysiology, clinical presentations, diagnosis, treatment, and complications. Childs Nerv Syst 29:739-744, 2013

22. Zeinalizadeh M, Sadrehosseini SM, Barkhoudarian G, Carrau RL: Reconstruction of the denuded nasoseptal flap donor site with a free fascia lata graft: technical note. Eur Arch Otorhinolaryngol 273:3179-3182, 2016

\section{Disclosures}

The authors report no conflict of interest concerning the materials or methods used in this study or the findings specified in this paper.

\section{Author Contributions}

Conception and design: Sadrehosseini, Zeinalizadeh, Nejat, Singh. Acquisition of data: Sadrehosseini, Zeinalizadeh, Habibi, Nejat, Brito da Silva. Analysis and interpretation of data: all authors. Drafting the article: Singh. Critically revising the article: Singh. Reviewed submitted version of manuscript: Zeinalizadeh, Habibi, Nejat, Brito da Silva, Singh. Approved the final version of the manuscript on behalf of all authors: Sadrehosseini.

\section{Supplemental Information \\ Videos \\ Video 1. https://vimeo.com/189952435.}

\section{Previous Presentations}

Partial results were presented in abstract form at the World Congress for Endoscopic Surgery in Chicago, Illinois, in May 2016.

\section{Correspondence}

Seyed Mousa Sadrehosseini, Department of Otolaryngology-Head \& Neck Surgery, Imam Khomeini Hospital Complex, Tehran University of Medical Sciences, Keshavarz Blvd., Tehran 1419733141, Iran.email: sadrehosseini@gmail.com. 